\title{
Disfunção massetérica e sialoadenite de refluxo: relato de caso
}

\author{
Masseteric dysfunction and reflux sialoadenite: case report \\ Disfunción massetérica y sialoadenita de reflujo: reporte de caso \\ Bianca Lopes de Andrade MARTINS \\ Dinahi Regina de Lira Miranda BRAGA \\ Lioney Nobre CABRAL \\ Escola de Ciências da Saúde, Universidade do Estado do Amazonas (ESA-UEA) 69065.001 Cachoeirinha.Manaus-AM, Brasil
}

\section{Resumo}

A sialoadenite é uma inflamação das glândulas salivares que pode ser de origem infecciosa ou não, caracterizada por edema, dor e diminuição ou ausência de salivação da glândula afetada. A redução do fluxo salivar pode ser encontrada também em casos de hipertrofia das glândulas parótidas, como observado nos casos de diabetes, alcoolismo, desnutrição, anorexia, bulimia e, dentre elas, a estenose ductal, que pode ocorrer, em razão de sialólitos, mas também devido à contratura muscular em indivíduos com disfunção muscular mastigatória, cronificada pela perda de dimensão vertical decorrente da não reabilitação protética e potencializada por razões ambientais diversas. Este trabalho apresentará um caso em paciente de 61 anos de idade, sexo feminino, com queixa de fortes dores na região de glândula parótida direita, edema ipsilateral, mioespasmo com presença de pontos gatilhos massetéricos e ordenha negativa, levando a hipótese diagnóstica de Sialoadenite de Refluxo. Houve indicação da confecção de um aparelho protético inferior com plano deslizante de resina acrílica para aumentar a Dimensão Vertical de Oclusão (DVO) e restabelecer a dinâmica maxilomandibular, regularizando o fluxo salivar do ducto parotídeo e restaurando a homeostasia glandular até a aquisição de novas próteses reabilitadoras totais para paciente.

Descritores: Glândula Parótida; Inflamação; Fisiopatologia; Músculo Masseter.

\section{Abstract}

Sialoadenitis is an inflammation of the salivary glands that may be of infectious origin or not, characterized by edema, pain and decreased or no salivation of the affected gland. The reduction of salivary flow can also be found in cases of hypertrophy of the parotid glands, as observed in cases of diabetes, alcoholism, malnutrition, anorexia, bulimia and, among them, ductal stenosis, which may occur due to sialoliths, but also due to muscular contracture in individuals with masticatory muscular dysfunction chronified by the loss of vertical dimension due to non-prosthetic rehabilitation and potentiated by diverse environmental reasons. This paper aims to present a case in 61 years old patient, women, with complain of severe pain in the right parotid gland region, with ipsilateral edema, myospasm with the presence of trigger points masseteric and negative milking, taking to diagnostic hypothesis as Sialoadenitis Reflux. A lower prosthetic device with an acrylic resin sliding plane was made to increase the Vertical Occlusion Dimension (OVD) and to restore the maxillomandibular dynamics, regulating the salivary flow of the parotid duct and restoring glandular homeostasis until the acquisition of new rehabilitation prostheses for patients.

Descriptors: Parotid Gland; Inflammation; Physiopathology; Masseter Muscle.

\section{Resumen}

La sialoadenitis es una inflamación de las glándulas salivares que puede o no tener origen infeccioso y se caracteriza por edema, dolor y disminución o ausencia de salivación de la glándula afectada. La reducción del flujo salivar puede encontrarse también en casos de hipertrofia de las glándulas parótidas, como se observa en los casos de diabetes, alcoholismo, desnutrición, anorexia, bulimia y, entre ellas, la estenosis ductal; esta puede ocurrir en razón de sialolitos o debido a la contractura muscular en individuos con disfunción muscular masticatoria cronificada por la pérdida de dimensión vertical, resultante de la falta de rehabilitación protética y potencializada por razones ambientales diversas. Este trabajo expondrá un caso en paciente de 61 años de edad, del sexo femenino, con queja de fuertes dolores en la región de glándula parótida derecha, edema ipsilateral, mioespasmo con presencia de puntos gatillos masetéricos y ordeño negativo, llevando la hipótesis diagnóstica de Sialoadenite de reflujo. Se indicó la confección de un aparato protético inferior con plano deslizante de resina acrílica para aumentar la Dimensión Vertical de Oclusión (DVO) y restablecer la dinámica maxilomandibular, normalizando el flujo salivar del ducto parotídeo y restaurando la homeostasia glandular hasta la adquisición de nuevas prótesis rehabilitadoras para el paciente.

Descriptores: Glándula Parótida; Inflamación; Fisiopatología; Músculo Masetero.

\section{INTRODUÇÃO}

O sistema estomatognático é a unidade funcional do corpo primordialmente responsável pela mastigação, fala e deglutição; seus componentes também atuam no paladar e na respiração. É composto por dentes, tecidos periodontais, mucosa bucal, língua, glândulas salivares, maxila e mandíbula, musculatura mastigatória e articulação temporomandibular. Além disso, há um intrincado sistema de controle neurológico que regula e coordena todas essas estruturas e componentes ${ }^{1}$.

A sialoadenite é uma inflamação das glândulas salivares que pode ser de origem infecciosa ou não, caracterizada por edema, dor e diminuição ou ausência de salivação da glândula afetada. Possui duas formas de manifestação clínica: aguda e crônica $^{2}$. A infecção do parênquima salivar se dá geralmente pela migração retrógrada de bactérias provenientes da cavidade bucal, através do ducto da glândula. Essas infecções acometem, com maior frequência, as glândulas salivares maiores, principalmente a parótida, por produzir saliva com menor atividade bacteriostática em relação à da glândula submandibular e por ser uma saliva serosa com poucas glicoproteínas. Alguns fatores favorecem a migração de bactérias, como: redução do fluxo salivar (devido à presença de cálculo e estenose ductal, desidratação, grandes perdas de sangue, diarreia, medicações xerostômicas as mais diversas, além das de ação anticolinérgica ou diurética), comprometimento da resistência do hospedeiro, má higiene bucal e cirurgias recentes (principalmente abdominais) $)^{2}$.

A redução do fluxo salivar pode ser encontrada também em casos de hipertrofia das glândulas parótidas, como observada nos casos de diabetes, alcoolismo, desnutrição, anorexia, bulimia e, também, decorrente de estenose ductal, promovida por alterações físicas de estruturas anatômicas 
adjacentes ao percurso do ducto de Stenon, como exemplo o mioespasmo massetérico e por contiguidade do músculo bucinador, presentes na disfunção muscular temporomandibular crônica ${ }^{3,4}$.

Sinais ou sintomas relacionados às atividades parafuncionais que demandam os músculos mastigatórios e, por conseguinte, a articulação temporomandibular, são observados em $80 \%$ a $90 \%$ da população. $\mathrm{Na}$ maioria das pessoas, esses comportamentos não provocam alterações clinicamente importantes, no entanto, entre $10 \%$ a $15 \%$ dos casos resultam em graves problemas clínicos e necessitam de atendimento específico. As consequências desses comportamentos podem incluir: desgaste dental excessivo, dores musculares craniofaciais, maloclusão severa, alterações articulares degenerativas, desarranjo do disco articular, mioespasmo, hipertrofia muscular, alterações auditivas, agravamento de lesões periodontais e destruição de trabalhos restauradores ${ }^{5}$.

Os tipos de tratamento incluem intervenções tanto clínicas quanto cirúrgicas. No tangente às sialoadenites, a chave para o seu tratamento, é o correto diagnóstico de sua fisiopatogenia e, em caso de hipossalivação ou mesmo assialia, reidratação da mucosa bucal com a utilização de sialogogos ou mesmo saliva artificial, além da ingestão de líquidos, apoio nutricional, compressas quentes, massagem da área afetada, manutenção de higiene bucal e adequada antibioticoterapia, em caso de origem infecciosa $^{2}$.

$\mathrm{O}$ conhecimento das disfunções musculares maxilomandibulares e sua relação com estruturas contíguas e toda a economia orgânica, sabendo os potenciais danos de relação, é um fator de grande interesse para todas as especialidades da odontologia, pois interfere diretamente no ato da mastigação, na dieta e na qualidade de vida do paciente, devido à sintomatologia exuberante por ele experimentada durante essas ações.

\section{CASO CLÍNICO}

Paciente do gênero feminino, 61 anos de idade, feoderma, agricultora, fumante, portadora de Diabetes Mellitus tipo 2, compareceu à Policlínica Odontológica da Universidade do Estado do Amazonas (UEA), se queixando de fortes dores na região de glândula parótida direita, com inchaço da mesma (Figura 1). Alegava ter o hábito de ranger sobre os dentes das próteses, além de sensação de queimação em sua boca e dificuldade de abri-la na dimensão desejada. Afirmou também que a dor começou fraca e foi aumentando com o passar dos dias, se tornando latejante e quando se alimentava havia uma agudização da dor.

Ao exame clinico, constatou-se a utilização de próteses totais, superior e inferior, mal adaptadas com dentes desgastados e perda de dimensão vertical.
A abertura máxima de boca, com as próteses no local, foi de $31 \mathrm{~mm}$, como visto na Figura 2.

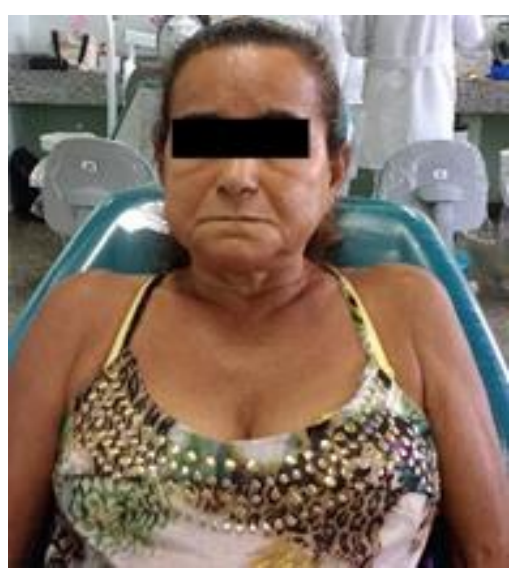

Figura 1: Aspecto inicial da paciente com edema na região da glândula parótida direita.

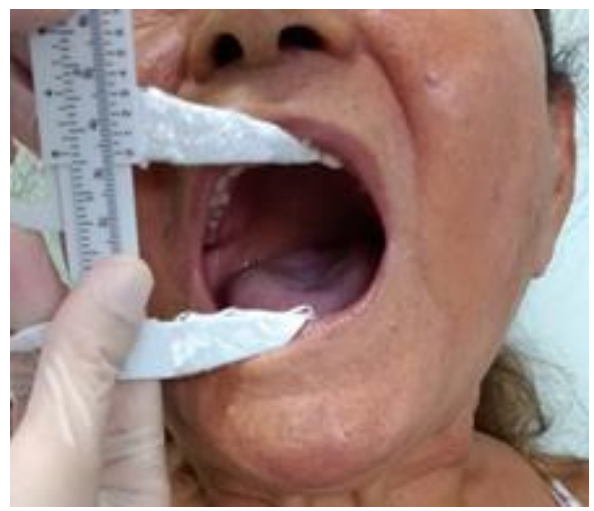

Figura 2: Abertura bucal máxima.

Havia sensibilidade articular à palpação do lado direito, além de sensação de zumbido em orelha ipsilateral e vertigem. Referiu dor à palpação nos músculos masseter, temporal, esternocleidomastóideo e trígono suboccipital também ipsilaterais. A presença de dor à palpação em inserção proximal, distal e corpo de músculo masseter superficial direito associada à redução da amplitude de abertura de boca, concorreu para o diagnóstico clínico de mioespasmo local (Figura 3).

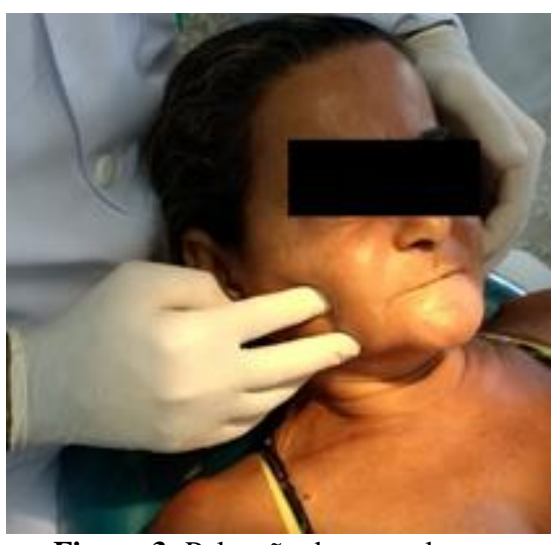

Figura 3: Palpação da musculatura.

A ordenha negativa associada à alteração inflamatória da glândula anexa a este principal músculo mastigatório cujo ducto o percorre, penetrando o bucinatório em ângulo, foi considerada 
na propedêutica, a relação entre a disfunção muscular e a alteração inflamatória glandular, planejando a terapêutica, a considerar o estado disfuncional muscular como fator importante na etiofisiopatogênese da sialoadenite de refluxo, devido à compressão física do ducto de Stenon.

Considerando a negatividade da ordenha desta glândula serosa, em primeira consulta, como visto na Figura 4, e as queixas de sensação de boca seca e ardência lingual, foi realizada a citologia esfoliativa em região dorsal de língua, por suspeita de candidose atrófica, não sendo esta confirmada. O laudo histopatológico destacou a ausência fúngica e confirmou somente glossite crônica

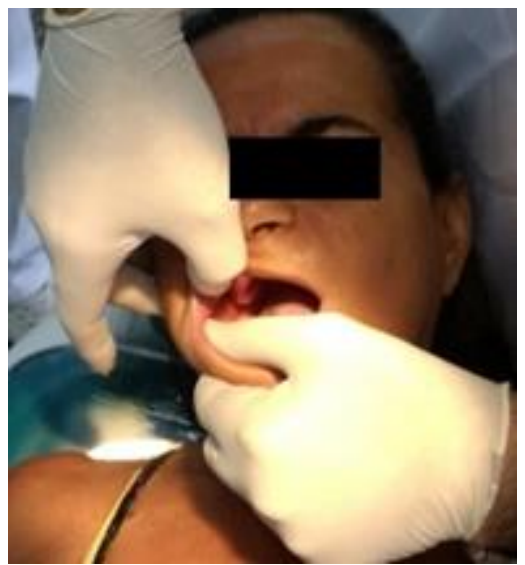

Figura 4: Realização da ordenha do ducto parotídeo.

Foi feita a construção do Guia de Interferência Oclusal (JIG) com silicone de condensação denso (Figura 5), associado à prescrição de uma associação de analgésico, anti-inflamatório e relaxante muscular (Beserol) e um protetor gástrico (Pantoprazol), para prevenir potenciais lesões estomacais, por um período de 7 dias.

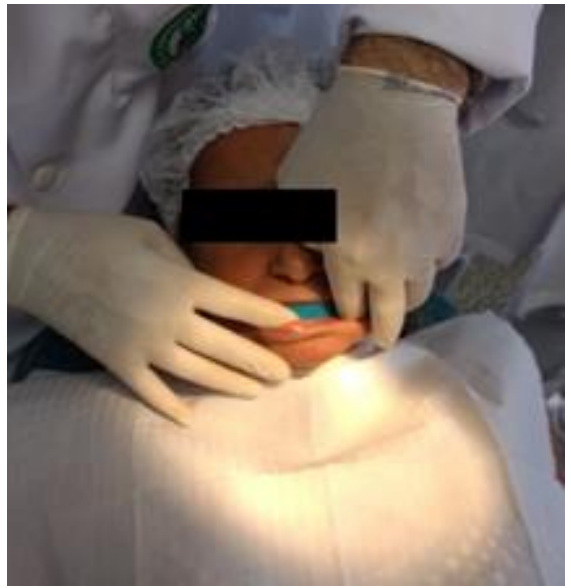

Figura 5: Confecção de JIG provisório com silicone de condensação pesado.

A paciente foi instruída a realizar fisioterapia com compressa de gelo (crioterapia) na região. Ademais, a paciente também foi orientada a praticar exercícios fisioterápicos, conforme preconizado por Okeson $^{6}$ :

1. Com as mãos espalmadas em forma de concha apoiadas abaixo da mandíbula, a paciente realiza abertura mínima (cerca de $1 \mathrm{~cm}$ ) contra a resistência das próprias mãos, em 3 (três) séries com 10 (dez) repetições, por 10 (dez) segundos, diariamente.

2. Com os dedos indicador e polegar entre os dentes, a paciente realiza abertura confortável lentamente orientada pelos próprios dedos, em 3 (três) séries de 30 (trinta) vezes contadas na abertura, diariamente. Vale salientar que os exercícios fisioterápicos eram executados em conjunto com a crioterapia e, ao longo do dia, a paciente usava o aparelho, retirando apenas para se alimentar.

Em seguida foi construída prótese inferior com plano deslizante em acrílico para aumentar a Dimensão Vertical de Oclusão (DVO) da paciente, até a confecção de novas próteses totais. Para tanto, utilizou-se a montagem dos modelos de gesso em articulador semiajustável (ASA), o qual reproduz movimentos maxilo-mandibulares. Inicialmente, realizou-se a moldagem da paciente nos arcos superior e inferior, com alginato. Obtidos os moldes, os mesmo foram vazados em gesso tipo IV. Na sequência fez-se o registro da mordida em relação cêntrica com o auxílio de cera rosa $n^{\circ} 7$. Para prosseguir a montagem dos modelos de gesso em articulador, foi necessário realizar o registro com o arco facial da posição da maxila em relação à base do crânio para a montagem do ramo superior do ASA. $\mathrm{Na}$ sequência os modelos maxilar e mandibular foram montados com o auxílio do registro em cera da relação cêntrica, mantendo-se, o ângulo condilar em $30^{\circ}$ e o ângulo de Bennett em $15^{\circ}$. O articulador foi assim enviado ao laboratório protético para confecção da prótese (Figura 6).

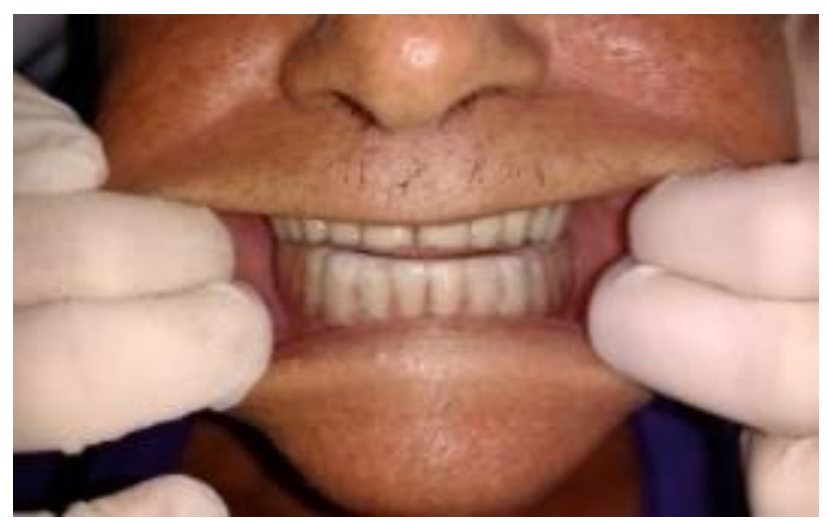

Figura 6: Prótese inferior com um plano deslizante em acrílico.

Na décima semana de tratamento, a paciente já não se queixava de fortes dores e referia apenas sensibilidade na região do músculo masseter. A paciente evoluiu de uma amplitude de $31 \mathrm{~mm}$ de abertura máxima para $39 \mathrm{~mm}$, saindo de uma situação de hipomobilidade articular para uma mobilidade progressiva de amplitude, bastante próxima à abertura normal, além de restauração da ordenha positiva, resgate da alteração de volume, 
sensibilidade de glândula parótida direita e redução da sensação de ardência bucal. (Figura 7).

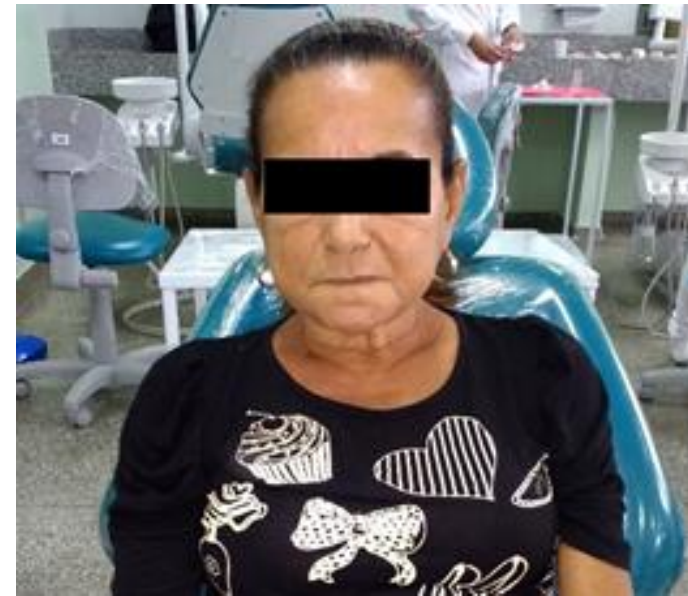

Figura 7. Paciente na décima semana de tratamento com aspecto facial mais harmônico.

\section{DISCUSSÃO}

A alteração inflamatória em glândula parótida é uma condição incomum, sendo importante na propedêutica desta condição, a história parafuncional mastigatória da paciente em decorrência das relações de proximidade anatômica entre as estruturas comprometidas: o masseter em espasmo e o ducto de Stenon que o percorre, com o fluxo salivar parotídeo, até fazer a curva e penetrar no bucinador para abrir-se no meio bucal.

Além do mais, a identificação no exame físico, de pontos gatilhos ativos nesta musculatura mastigatória e cervical do lado direito, a dificuldade de abertura de boca, zumbido em orelha ipsilateral e vertigem foram os sinais apresentados nesse caso que levaram ao diagnóstico de mioespasmo do principal músculo elevador mandibular, como consequência dos hábitos bruxistas com decorrente distúrbio muscular temporomandibular e alterações vestibulococleares. A ordenha negativa e o inchaço da glândula parótida concorreram para a hipótese diagnóstica de sialoadenite de refluxo, onde na estenose do ducto de Stenon, a saliva produzida ao invés de ganhar o meio bucal retornava à glândula, lesando-a e provocando o quadro inflamatório, queixa principal que levara a doente à procura do Serviço estomatológico.

Os sinais e sintomas presentes, as manobras semiotécnicas efetuadas, a anamnese e os exames complementares foram importantes e decisivos para a hipótese diagnóstica, possibilitando uma abordagem terapêutica eficaz para o distúrbio muscular temporomandibular primário com consequente prova terapêutica para a alteração glandular presente, melhorando o quadro sintomático da paciente que já havia passado por vários serviços em busca de uma solução para a intensa dor experimentada, relatando alívio progressivo com a terapia implementada fármacos relaxantes musculares associados ao uso de aparelho protético com pista deslizante e fisioterapias craniomandibulares e crioterapia concomitante, o que condiz com as mesmas utilizadas por outros autores $^{7-10}$ na resolução de seus casos - em razão do relaxamento e reorganização muscular progressiva e retorno do fluxo salivar confirmado na ordenha positiva e na melhora da sensação xerostômica e de queimação na boca.

Diante da ausência de padrão-ouro para a terapia das disfunções temporomandibulares, em vista de suas inúmeras possibilidades etiofisiopatogênicas, as modalidades terapêuticas não-invasivas reversíveis são preferidas, além do que é crucial estabelecer um plano individual de reabilitação complexa para o paciente. Uma das terapias não invasivas mais eficientes é a fisioterapia, especialmente exercícios associados à crioterapia ou termoterapia $^{11}$, tendo sido utilizado neste caso.

Com a perda dos dentes e sua consequente substituição por próteses totais, ocorrem reabsorções contínuas e progressivas no processo alveolar, que aliadas ao desgaste dos dentes artificiais decorrente do uso prolongado das próteses, são capazes de causar alterações nas relações intermaxilares, levando a redução da DVO, aumento do espaço interoclusal e uma rotação anterior da mandíbula ${ }^{12}$. Fato este que, na paciente em questão, em razão da parafuncionalidade presente concorreu para a presença de pontos gatilhos em músculos mastigatórios e cervicais, além da espasticidade massetérica.

No atendimento de pacientes com DTM, as placas oclusais são dispositivos simples, reversíveis e não-invasivos, que contribuem com o relaxamento muscular e alívio da dor, permitindo uma estabilidade neuromuscular. Tais dispositivos promovem alterações na dimensão vertical de oclusão e eliminam a má oclusão indicadas no diagnóstico e tratamento das DTMs ${ }^{13}$. Na paciente em questão, utilizamos um dispositivo integrado ao seu aparelho protético inferior similar a uma placa miorrelaxante, denominado pista deslizante.

Importante salientar que a simples instalação de uma placa ou pista deslizante integrada a um aparelho protético, sem os devidos cuidados e instruções aos pacientes e, principalmente, sem o estreito relacionamento entre paciente e profissional, poderá nos levar a resultados frustrantes na utilização dessa modalidade de tratamento. Assim, não se devem utilizar as placas oclusais como uma única modalidade de tratamento, mas em conjunto com outros programas ${ }^{9}$, como planejado neste caso.

Sem a colaboração da paciente durante todo o tratamento para manter a rotina diária de exercícios fisioterápicos, o uso da pista deslizante associada ao aparelho protético, dos medicamentos prescritos, e com todo o reforço psicológico, não seria possível um resultado tão satisfatório quanto. Porém devido a 
evasão da paciente para proservações mensais e anuais não se tem informações sobre recidiva do caso.

\section{CONCLUSÃO}

Diante do resultado favorável obtido nesse caso clínico, as técnicas utilizadas, por serem não invasivas e reversíveis, sugere-se utilização das mesmas pelo clínico como alternativa segura e efetiva para o tratamento da disfunção massetérica e da sialodenite de refluxo.

Conclui-se também, que a perda de dimensão vertical de oclusão (DVO) acarreta em disfunções dos músculos mastigatórios e que associado a outros problemas sistêmicos e ambientais da paciente desencadeou a sialadenite de refluxo pela estenose do ducto de Stenon.

A chave para o sucesso no tratamento foi o correto diagnóstico da fisiopatogenia da doença associado a um plano individual de reabilitação complexa e contando sempre com a colaboração da paciente.

\section{REFERÊNCIAS}

1. Barbosa VCS, Barbosa FS. Fisioterapia nas disfunções temporomandibulares. $1^{\text {a }}$ Ed. São Paulo: Phorte; 2009. Capítulo 1, Sistema estomatognático; p. 21-61.

2. López-Alvarenga RL, Martins PCA, Seabra RC, Carneiro MA, Souza LN. Sialoadenite supurativa aguda em glândula submandibular. Rev cir traumatol buco-maxilo-fac. 2009;9(3):29-34.

3. Navazesh M, Brightman VJ, Pogoda JM. Relationship of medical status, medications, and salivary flow rates in adults of diferente ages. Oral Surg Oral Med Oral Radiol Endod. 1997; 81(2):172-76.

4. Baptista Neto C, Sugaya NN. Tratamento da xerostomia em pacientes irradiados na região da cabeça e do pescoço. Rev Biociências. 2004; 10(3):147-151.

5. Fricton JR, Dubner R. Dor orofacial e desordens temporomandibulares. São Paulo: Santos; 2003.

6. Okeson JP. Tratamento das desordens temporomandibulares e oclusão. 6. ed. São Paulo: Elsevier; 2008. p. 229-66.

7. Carvalho JPM. Disfunção Temporomandibular Muscular Miofascial e de Mioespasmo: Relato de Caso. In: Programa. Congresso Alagoano de Odontologia; 2015; Maceió, Brasil. Maceió, AL: Maceiodonto; 2015.

8. Avrella A, Heck EM, Hurtig GD, Ceron LP, Pasinato MDE, Spohr $\mathrm{P}$ et al. Terapia em paciente com disfunção temporomandibular muscular relato de caso. J Oral Invest. 2014;3(2):4-7.

9. Almilhatti HJ, Camparis CM, Bönecker G, Ribeiro RA. Como aumentar o índice de sucesso no tratamento com placas oclusais miorrelaxantes.
J Bras Oclusão, ATM Dor Orofacial. 2002;2(8):340-43.

10.Santos CC, Fernandes KJM, Miranda ECLS, Pordeus SS. Disfunção temporomandibular muscular miofascial (DTM) e hipermobilidade articular: relato de caso clínico. In: Congresso Alagoano de Odontologia - Maceiodonto; 2015; Maceió, Brasil.

11.Halmova K, Holly D, Stanko P. The influence of cranio-cervical rehabilitation in patients with myofascial temporomandibular pain disorders. Bratisl Med J. 2017;118(11):710-13.

12.Fonseca-Silva AS, Uchoa ES, Nóbilo MAA, Bérzin F. Avaliação eletromiográfica da influência da placa oclusal sobre o orbicular da boca em indivíduos portadores de próteses totais com disfunção temporomandibular e dor orofacial. Rev Odonto Cienc. 2007; 22(57):263-68.

13.Strini PJSA, Sousa GC, Bernardino Júnior R, Strini PJSA, Fernandes Neto AJ. Alterações biomecânicas em pacientes portadores de Disfunção Temporomandibular antes e após o uso de dispositivos oclusais. Rev Odonto. 2009; 17(33):42-7.

\section{CONFLITO DE INTERESSES}

Os autores declaram não haver conflitos de interesse.

\section{AUTOR PARA CORRESPONDENCIA}

\section{Bianca Lopes de Andrade Martins}

bia_lam@hotmail.com
Submetido em 22/06/2018

Aceito em 04/10/2018 